\title{
Sequential auctions with synergies: an experimental analysis
}

Citation for published version (APA):

Leufkens, K., Peeters, R. J. A. P., \& Vorsatz, M. (2006). Sequential auctions with synergies: an experimental analysis. METEOR, Maastricht University School of Business and Economics. METEOR Research Memorandum No. 040 https://doi.org/10.26481/umamet.2006040

Document status and date:

Published: 01/01/2006

DOI:

10.26481/umamet.2006040

Document Version:

Publisher's PDF, also known as Version of record

\section{Please check the document version of this publication:}

- A submitted manuscript is the version of the article upon submission and before peer-review. There can be important differences between the submitted version and the official published version of record.

People interested in the research are advised to contact the author for the final version of the publication, or visit the DOI to the publisher's website.

- The final author version and the galley proof are versions of the publication after peer review.

- The final published version features the final layout of the paper including the volume, issue and page numbers.

Link to publication

\footnotetext{
General rights rights.

- You may freely distribute the URL identifying the publication in the public portal. please follow below link for the End User Agreement:

www.umlib.nl/taverne-license

Take down policy

If you believe that this document breaches copyright please contact us at:

repository@maastrichtuniversity.nl

providing details and we will investigate your claim.
}

Copyright and moral rights for the publications made accessible in the public portal are retained by the authors and/or other copyright owners and it is a condition of accessing publications that users recognise and abide by the legal requirements associated with these

- Users may download and print one copy of any publication from the public portal for the purpose of private study or research.

- You may not further distribute the material or use it for any profit-making activity or commercial gain

If the publication is distributed under the terms of Article $25 \mathrm{fa}$ of the Dutch Copyright Act, indicated by the "Taverne" license above, 
Kasper Leufkens, Ronald Peeters, Marc Vorsatz

Sequential auctions with synergies:

An experimental analysis

$\mathrm{RM} / 06 / 040$

JEL code: C91, D44

\section{METEबrR}

Maastricht research school of Economics of TEchnology and ORganizations

Universiteit Maastricht

Faculty of Economics and Business Administration

P.O. Box 616

NL - 6200 MD Maastricht

phone : ++31 433883830

fax : ++31433884873 



\title{
Sequential auctions with synergies: An experimental analysis*
}

\author{
Kasper Leufkens ${ }^{\dagger} \quad$ Ronald Peeters ${ }^{\dagger} \quad$ Marc Vorsatz $^{\dagger}$
}

September 10, 2006

\begin{abstract}
In this paper we show experimentally that in a sequential auction the presence of synergies leads to more overbidding which in turn may result in bankruptcies. In line with theoretical predictions we find that the seller benefits from the buyers' synergies. In contrast to theory the buyers also benefit from these synergies. Moreover, opposed to theory and many empirical findings we do not observe declining prices. Finally we find that the overbidding is increasing in the valuation of the object on which the synergy does not materialize and we attribute this finding to anchoring.
\end{abstract}

JEL Classification: C91, D44.

Keywords: Bankruptcy, Experiment, Sequential Auction, Synergies.

\section{Introduction}

A distinguishing characteristic of procurement auctions is their sequential nature. Construction contracts, military procurement, and the uncoordinated sequence of European spectrum auctions during 2000 and 2001 are all examples of this sequentiality (Reiß and Schöndube, 2002). Furthermore, large-scale projects are often divided into small subprojects which are then procured sequentially. This can be the consequence of the complexity of the project or the fact that too few firms have sufficient resources to complete the project as a whole (Yildirim, 2004).

In multi-unit procurement auctions winning multiple contracts can lead to cost advantages due to synergies. These synergies can be material, for instance owning specialized equipment, or intangible, like expertise. A consequence for the settings above is that bidders' valuations are stochastically dependent across auctions. Bidders then face an exposure problem as they can end up winning contracts that are too expensive if the complementary contracts are not also won.

\footnotetext{
${ }^{*}$ We would like to thank Martin Strobel, Jan Potters and the conference and seminar participants in Amsterdam (EARIE 2006) and Maastricht for helpful comments and suggestions. Financial support by the Dutch Science Foundation (NWO) is gratefully acknowledged.

${ }^{\dagger}$ Department of Economics, Maastricht University, P.O. Box 616, 6200 MD Maastricht, The Netherlands. Email: \{K.Leufkens, R.Peeters, M.Vorsatz\}@algec.unimaas.nl. The first author is the corresponding author.
} 
Also auctions of collectibles exhibit exposure problems. Suppose one is a collector of paintings from Picasso's blue period. As the collection of paintings grows, the values of the missing paintings increase. Imagine having all but one painting, the value of this painting is now much higher than when one started the collection. With more and more memorabilia being traded via popular online auction sites, collectors can anticipate that complementarities for objects auctioned now will become available somewhere in the future.

Much interest in multi-unit auctions was generated by the spectrum auctions that were conducted all over the world. Typically, exposure problems were present in these auctions due to synergies. Cramton (2002), for instance, argues that the presence of synergies is one of the reasons why the revenue from the spectrum auction in the United Kingdom was so high.

In order to get some guidance on which auction rules to implement in the spectrum auctions and similar complex environments, experimental analyses were conducted. Some of these experiments explored situations in which theory gave little guidance (Plott, 1997, and Ledyard et al., 1997) while others tested the feasibility of certain auction mechanisms (Brenner and Morgan, 1997, and Isaac and James, 2000). Recent experimental research analyzes the effect the presence of an exposure problem has in simultaneous multi-unit auctions more thoroughly. Englmaier et al. (2004) compare a chopstick auction to a second-price sealed-bid auction that does not contain the exposure problem and find that the chopstick auction is less efficient but yields more revenue. Kagel and Levin (2005) investigate the tension between demand reduction and positive synergies. They test both uniform-price sealed-bid auctions and ascending clock auctions and find that bidders are responsive to the underlying forces, but in the clock auctions there is a general reluctance to overbid when this is optimal.

Surprisingly, few experimental analyses on the exposure problem in sequential auctions have been conducted. Plott (1997) and Ledyard et al. (1997) report on sequential auction experiments with the exposure problem. Their focus is on finding the optimal auction mechanism and they find that the sequential auction is outperformed by the simultaneous auction in terms of efficiency and revenue. Février et al. (2004) analyze sequential auctions of two objects with and without the buyer's option, which means that the winner of the first object has the option to also buy the second object at the winning price, and consider settings in which the valuation for the second object increases if the first is won. Their focus is on comparing different auction formats in terms of revenue and the usage of the buyer's option. They note that subjects bid too conservatively compared to theory which may well be attributed to the presence of the exposure problem.

The theoretical literature on sequential auctions with synergies focusses mainly on price trends. Branco (1997) showed that in a sequential auction of homogeneous objects a decreasing price trend, better known as the declining price anomaly, can be explained by the presence of positive synergies. Tang Sørensen (2006) considers a similar model for stochastically equivalent objects. In both articles synergies are modeled as a positive constant that is added to the valuation which means that for low valuations the marginal synergy is infinite. 
Jeitschko and Wolfstetter (2002) overcome this problem by modeling synergies as an increase in the probability of having a high valuation for the second object.

Governments may not only be interested in revenues but also the social consequences of auction outcomes. Therefore Leufkens et al. (2006) analyze not only price trends and revenues, but also the consequences the presence of positive synergies has for bidders. They consider a sequential auction of two stochastically equivalent objects where the valuation of the second object is uncertain during the first auction and positive synergies are present. It is found that bidders suffer instead of benefit from the presence of synergies. In contrast to single private value auctions, it is not guaranteed anymore that in equilibrium bidders do not make losses which can lead to bankruptcy. Furthermore, it turns out that the expected payoff for bidders is decreasing in the size of the synergies.

As argued above, many auction settings can be characterized as being sequential in nature and synergies are often present in such settings. Given these theoretical predictions and the fact that appropriate field data is impossible to get, an experimental analysis of the consequences the presence of positive synergies has in a sequential auction can give interesting insights. Especially the responsiveness of the bidding, and the problem of bankruptcy in particular, to the presence and the size of the synergy are important for public policy. In this paper we therefore experimentally analyze a model similar to Leufkens et al. (2006) and compare a baseline treatment without synergies to two treatments with positive synergies of different size.

We find that the presence of positive synergies, and thus the exposure problem, indeed changes the sequential auction fundamentally. The presence of synergies leads to an increase in the overbidding and the number of round bankruptcies. However, the responsiveness to an increase in the size of the synergy factor is much smaller than predicted by theory and bidding does not get as competitive as expected. Consequently, we find that when the possible synergies are large, bidders do benefit from them. The seller always benefits from the bidders' synergies but not as much as expected. The price in the first auction of a round does not increase enough to observe declining prices. Finally, in the two treatments with positive synergies we find that the overbidding is increasing in the valuation of the object on which the synergy does not materialize and we attribute this finding to anchoring.

This paper is organized as follows. In the next section the model and its equilibrium are discussed. Section 3 describes the experimental design and the laboratory procedures. The hypotheses are given in Section 4 and in Section 5 the results are presented. In Section 6 we discuss some behavioral findings of our experiment. The conclusion can be found in Section 7. Appendix A contains the instructions and the control questions and Appendix B the post experimental questionnaire. 


\section{The auction setting}

We consider a private value auction of two stochastically equivalent objects. The objects are auctioned sequentially using the second-price sealed-bid format. ${ }^{1}$ Bidders' valuations are uniformly distributed between 0 and 100 and the same four bidders participate in both auctions. Valuations are individually uncorrelated and drawn independently according to this distribution. Furthermore, the valuation for the second object is not known during the first auction. The bid and valuation in auction $k$ of bidder $n$ are denoted by $b_{k n}$ and $v_{k n}$.

Although no bidder knows his valuation of the second object during the first auction, it is common knowledge that winning the first object increases this valuation by factor $s \geq 1$. If bidder $i$ then wins the first object, his valuation in the second auction (weakly) increases from $v_{2 i}$ to $s v_{2 i}$, but does not have any effect on $v_{1 i}$. Consequently, winning the first auction leads to an increase in the expected instantaneous payoff of the second auction. After each auction bidders are informed whether or not they won the object, the price at which the object was sold, and their payoff, which is the difference between the valuation and the price when the auction is won and zero otherwise.

The way in which positive synergies are modeled is comparable to the way Black and De Meza (1992) model negative synergies. Attributing cost reductions only to the second object makes sense considering the order in which projects are executed. For instance, expertise is created during the first project and this gives benefits for the second or specialized equipment is needed which then does not need to be acquired for a second project. This way of modeling synergies also ensures that there is a relationship between the increase in valuation due to synergies and the intrinsic value of the second object. Although the synergy factor is known a priori, the actual gain due to synergies depends on the realized second auction valuation.

The model resembles Engelbrecht-Wiggans' (1994) and Tang Sørensen's (2006) models by having bidders' valuations drawn independently across objects and only be known at the start of each auction. This is applicable when there is a time gap between two following auctions. Then, the exact valuation of the second object is uncertain at the time of the first auction, but it is known that a similar project will be auctioned in the future.

The expected instantaneous payoff of auction 1 for bidder $i$ prior to the realization of the valuations for this auction is denoted by $\bar{\pi}_{1 i}$. The expected instantaneous payoff of auction 2 for bidder $i, \bar{\pi}_{2 i}$, is prior to the realization of the valuations for this auction but given the outcome of the first auction. Finally, $\bar{p}_{k}$ is the expected price of auction $k, \bar{R}$ is the expected revenue from both auctions for the seller and $\bar{\mu}_{i}$ is the expected payoff from both auctions for bidder $i$, and all are prior to the realization of any valuation.

The symmetric equilibrium for four risk-neutral bidders and $s \geq 1$ is given below (see Leufkens et al. (2006)). All hypotheses will be formulated with respect to this risk-neutral

\footnotetext{
${ }^{1}$ Although many applications are in procurement settings, we analyze 'highest bid wins' auctions for expositional ease and without loss of generality.
} 
equilibrium specification.

$$
\begin{array}{ll}
b_{1 i}^{*}=v_{1 i}+\left(50 s-75+25 \frac{1}{s}\right) & \bar{\pi}_{1 i}=5-\frac{1}{4}\left(50 s-75+25 \frac{1}{s}\right) \\
b_{2 i}^{*}=\left\{\begin{array}{lll}
v_{2 i} & \text { if auction } 1 \text { is lost } \\
s v_{2 i} & \text { if auction } 1 \text { is won }
\end{array}\right. & \bar{\pi}_{2 i}= \begin{cases}5 \frac{1}{s} & \text { if auction } 1 \text { is lost } \\
50 s-75+30 \frac{1}{s} & \text { if auction } 1 \text { is won }\end{cases} \\
\bar{p}_{1}=60+\left(50 s-75+25 \frac{1}{s}\right) & \bar{\mu}_{i}=5+5 \frac{1}{s} \\
\bar{p}_{2}=75-15 \frac{1}{s} & \bar{R}=50 s+60+10 \frac{1}{s} .
\end{array}
$$

The intuition for the equilibrium bidding strategies is straightforward. The second auction is a one-shot second-price sealed-bid auction. Consequently everybody will simply bid his valuation. The gain from winning the first auction is not only the direct payoff from the first auction, but also the increase in the expected instantaneous payoff of the second auction. This increase equals the difference between the $\bar{\pi}_{2 i}$ of having won or lost the first auction. For the remainder of this paper we will refer to this difference as $\Delta$. Since it is a second-price auction, it is weakly dominant to bid one's valuation plus $\Delta$ in the first auction.

\section{$3 \quad$ Experimental design and procedures}

To analyze the impact the presence of positive synergies has on a sequential auction of two objects we designed three different treatments. In the baseline treatment, S1.0, there were no synergies and thus the auctions were independent second-price sealed-bid auctions. In treatment S1.5 the second auction valuation was multiplied by 1.5 if the first auction was won. Finally, we had a treatment with even larger synergies, S2.0, where the second auction valuation was multiplied by 2.0 .

Subjects were randomly assigned to groups of four bidders that played the sequential auction for fifty rounds of two auctions each. It was common knowledge that the group composition did not change during the experiment, but collusion is not an issue with four bidders (see Huck et al., 2004). Subjects did not know their second auction valuation during the first auction. In the two treatments with synergies subjects were informed during each first auction of a round that the second auction valuation would be upgraded by factor $s$ if this auction was won. In the second auction the winner of the first auction observed both his drawn and his upgraded valuation. After an auction each subject received an overview of the auction outcome; his (upgraded) valuation, the bid submitted, whether or not the auction was won, the price at which the object was sold and the payoff from the auction. Subjects never (directly) observed the valuations and bids of others. At the end of each round subjects also received an update on their total payoff.

Bidders' valuations were integers from the interval [1,100] and were expressed in Experimental Currency Units (ECU). To maximize the comparability of the treatments, four series of valuations were fixed and used for all groups of four bidders. In the first and last 25 rounds 
of an experimental session, every integer between 1 and 100 was drawn exactly once in both auctions. Moreover, we opted for a balanced setting meaning that all bidders in a group had approximately, over the course of a session, identical average valuations and the same number of times the highest valuation. Subjects could submit any bid between 0 and 999 ECU. Bids did not have to be integers. In case of tied highest bids the winner was randomly selected from these bidders.

The experiments were conducted in the experimental laboratory of the faculty of economics and business administration at Maastricht University in March 2006. In total 108 undergraduate students participated and sessions lasted about 80 minutes. We conducted three sessions of twelve subjects per treatment which resulted in nine independent observations per treatment. The groups were formed randomly and group members were anonymous to each other. Subjects earned ECU during the experiment which were converted into Euros at a known exchange rate at the end of the experiment. For S1.0, S1.5 and S2.0 the exchange rate for 1 ECU was respectively 2.00, 2.40 and 2.67 Eurocents. The average payoff was $€ 15.60$ including an initial endowment of $€ 5$.-. None of the subjects received a negative payoff.

The experiment was announced via email and subjects could register online using their matriculation number. This ensured that students could participate only once. When students arrived at the laboratory they had to draw a card from a deck that determined at which computer terminal they were placed. In case more than twelve students showed up for a session, we randomly determined the students that could not participate and paid them $€ 3$.- compensation. All interactions took place via computers that were connected to a network and the computer terminals were placed is such a way that subjects could not see the screens of others or make eye contact with them. The experiment was programmed in z-Tree (Fischbacher, 1999). Before the start of a session the subjects read the instructions and were allowed to privately ask questions which were then privately answered. After reading the instructions subjects had to fill out a couple of control questions that tested their understanding of the instructions. ${ }^{2}$ One of the experimenters checked the answers and the experiment only started after all subjects answered each question correctly. After a session had finished the subjects were asked to fill out a questionnaire to give the experimenters some background information. ${ }^{3}$ Payment took place privately and subjects had to leave the laboratory immediately once paid.

\section{Hypotheses}

We used the same valuations in all treatments which means that differences across treatments in the first auction of a round can be purely attributed to differences in behavior. In

\footnotetext{
${ }^{2}$ See Appendix A for the instructions and control questions for the treatments S1.0 and S2.0.

${ }^{3}$ See Appendix B for this post-experiment questionnaire.
} 
all treatments the second auction is a simple one-shot second-price sealed-bid auction and although the equilibrium bidding strategies are identical, comparisons across treatments are more complicated. First of all, due to the upgrading for the winner of the first auction the valuations are not identically distributed anymore. Second, the winner of the first auction can have an upgraded valuation that is larger than 100. He then has the highest valuation for sure and any bid above 100 can then be submitted if one assumes that all other subjects are fully rational. ${ }^{4}$ These bids are then susceptible to large variations and any bid above 100 can be classified as equilibrium bidding. Since these bids can be so extreme that they heavily influence aggregated group data, we will not do direct comparisons across treatments for bidding behavior in the second auction. However these problems do not (or only marginally) carry over to the prices and payoffs in the second auction, which therefore can be compared.

In a single second-price sealed-bid auction bidders bid truthful and the auction is therefore efficient. From the equilibrium bidding strategies in Section 2 it can be concluded that the presence of positive synergies does not reduce the efficiency. In the first auction of a round all risk-neutral bidders add the same positive constant to their valuation, which means that the bidder with the highest valuation still wins. Thus, we should not observe differences among the efficiency in the first auction for the three treatments.

Hypothesis 1. The synergy factor has no effect on the efficiency in the first auction.

The bidding in the first auction should differ significantly across treatments, because the presence of positive synergies leads to more aggressive bidding. In the baseline treatment theory predicts that there is no overbidding at all, but it is a well established experimental result that some slight overbidding is observed in second-price sealed-bid auctions (Kagel, et al., 1987, and Kagel and Levin, 1993). According to theory a risk-neutral bidder should bid 16.67 above his valuation in treatment S1.5 and 37.50 in treatment S2.0. Hence, we expect more overbidding the larger the synergy factor.

Hypothesis 2. The overbidding in the first auction increases in the synergy factor.

Previous theoretical and experimental research on sequential auctions with synergies only focussed on revenue and price trends. First, we will test whether the prices in the first auction indeed increase with the synergy factor. The difference with Hypothesis 2 is that the price is only one of the four bids submitted in an auction.

Hypothesis 3. The price in the first auction increases in the synergy factor.

The expected prices of both auctions in a round are higher when positive synergies are present. In the first auction all bidders bid above their valuation and in the second auction there is one bidder that bids higher than without synergies. Consequently, the seller's expected revenue is larger when synergies are present and increasing in the synergy factor. This can also be seen from the equilibrium specification in Section 2.

\footnotetext{
${ }^{4}$ See Güth et al. (2005) for an experimental analysis of an asymmetric second-price sealed-bid auction.
} 
Hypothesis 4. The seller's revenue increases in the synergy factor.

Weber (1983) shows that if bidders demand a single unit, the prices in a sequential auction of identical objects are a martingale; that is, in expectation prices drift neither up nor down. However there is ample empirical evidence of declining price trends in sequential auctions, which is known as the declining price anomaly or afternoon effect. For instance, declining prices are observed in wine auctions (Ashenfelter, 1989, and McAfee and Vincent, 1993), real estate auctions (Ashenfelter and Genesove, 1992), and impressionist and modern paintings auctions (Beggs and Graddy, 1997). The declining price anomaly has also been found in experimental settings (Burns, 1985, Keser and Olson, 1996, and Neugebauer and PezanisChristou, 2005). Branco (1997) was the first to attribute the declining price anomaly to the presence of positive synergies, a theoretical finding that was extended to heterogenous objects by Jeitschko and Wolfstetter (2002).

In our setting, all bidders increase their bids in the first auction by $\Delta$ and the expected price then increases by this amount. In the second auction the bid of the bidder that won the first auction increases when synergies are present and for the others it remains the same. This will only lead to an increase in the price of the second auction in three situations. Namely, if for the first auction winner: the upgrading increases his valuation from second highest to highest, the upgrading increases his valuation but it remains the second highest, or the upgrading increases his valuation from less than second highest to second highest. Consequently, for uniformly distributed valuations declining prices will always be observed in expectation (Leufkens et al., 2006). ${ }^{5}$

\section{Hypothesis 5. Declining prices are observed if and only if positive synergies are present.}

The uncertainty concerning the benefits from synergies leads to an exposure problem for bidders. All bidders bid above their valuation in the first auction and it is possible that the instantaneous payoff is negative. Although winning the first auction increases the probability of winning the second auction, this is far from sure. The winner of the first auction may not win the second auction or win it but still not recover the loss from the first auction and then the total payoff from a round is negative. The probability of a negative total payoff from a round increases with the synergy factor and theoretically this probability equals $0,0.29$ and 0.41 for respectively S1.0, S1.5 and S2.0. Thus we expect to observe negative round payoffs more frequently the larger the upgrading is.

Hypothesis 6. The frequency with which subjects receive a negative payoff from a round increases in the synergy factor.

\footnotetext{
${ }^{5}$ Theoretically the difference between the expected price in the first and second auction increases in the synergy factor. A statistical analysis of this can only be done on a group level which means that opposing trends might cancel out. Also it is not obvious whether this comparison should be done based on the absolute or relative difference in prices. Therefore we abstain from doing such an analysis.
} 
Rather paradoxical, the ex-ante expected total payoff, $\bar{\mu}_{i}$, is decreasing in the synergy factor. This means that the larger the possible benefit from synergies becomes, the smaller the expected total payoff of the bidders will be. The first auction winner pays besides the price he would pay if it was a single auction, the difference in the expected instantaneous payoff of the second auction between having won or lost the first auction. This means that the ex-ante expected total payoff of the two sequential auctions equals the expected payoff of a single auction without synergies plus the expected instantaneous payoff from the second auction given the first auction is not won. In the experiment we should then observe that subjects earn less ECU the larger the upgrading factor is.

Hypothesis 7. Earnings in ECU are decreasing in the synergy factor.

\section{$5 \quad$ Results}

In this section we present the results of our experiments. First, we discuss some descriptive statistics of the data we collected. Since our hypotheses mainly regard the first of the two auctions in a round, we concentrate exclusively on the overbids of the first auction for the moment. It has already been mentioned in Section 3 that we have nine independent observations for each treatment. Four subjects formed one group and therefore we have 36 observations for every round of a treatment. For every observation we calculate the overbid by subtracting the bidder's valuation from his bid. In Figure 1, we plot the first quartile, median, average, and third quartile, of these overbids.
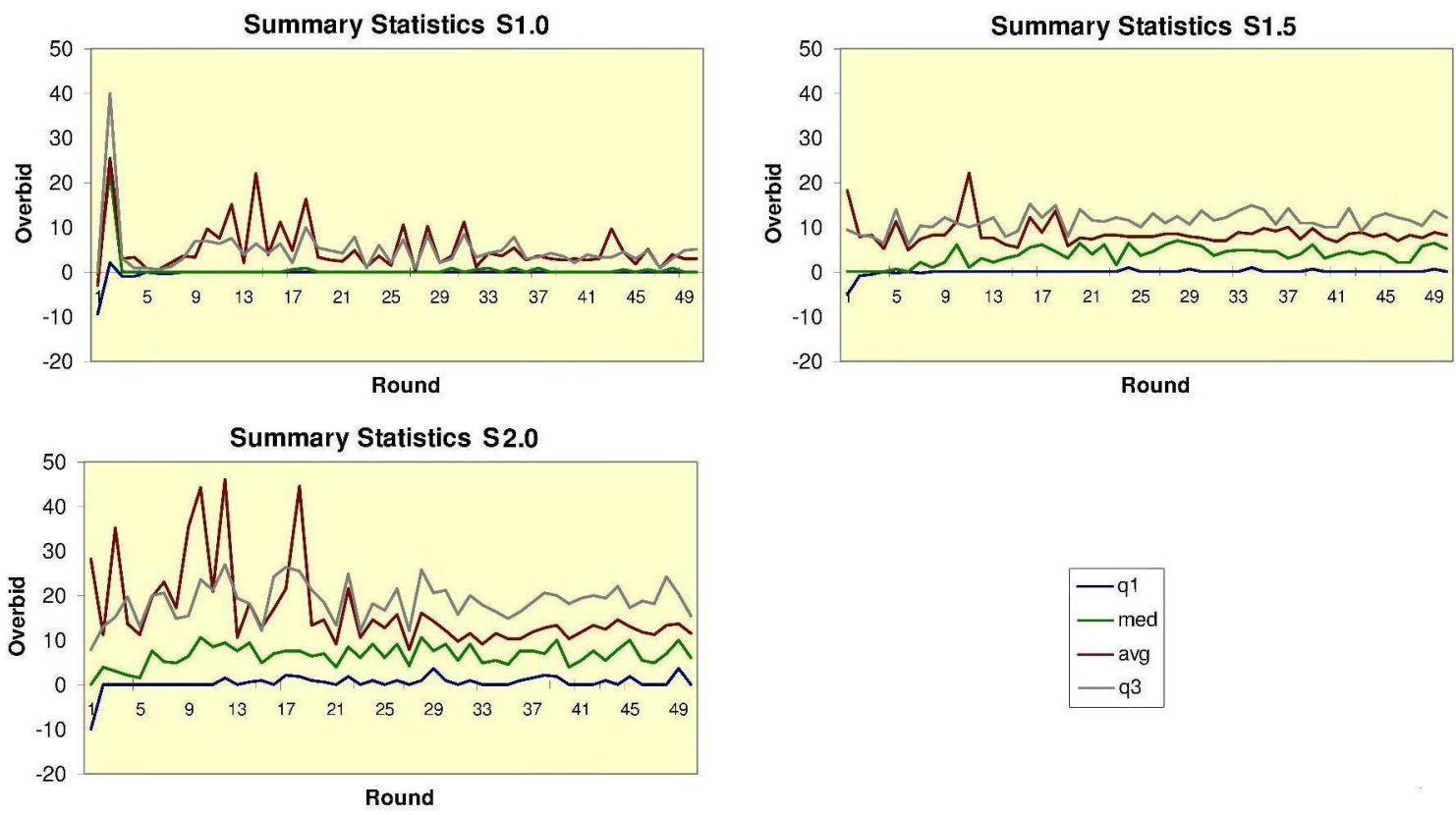

Figure 1: Summary statistics of overbids per round.

For S1.0 it can be observed that the first quartile and median are virtually zero in all rounds. The average and the third quartile show some variance until round 30 . In particular, 
the average lies rather often above the the third quartile which is a clear sign of outliers. Both the average and the third quartile exhibit less variance for later rounds and converge to values around five.

For S1.5 we observe that the first quartile is almost always zero. The median increases slightly over the first rounds from zero to about five where it remains ever after. The average lays always above the median (this, by the way, is true for all treatments) and above the third quartile for some early rounds. It can also be seen that the average and the third quartile converge to values around eight and twelve respectively.

With respect to the third treatment, S2.0, we identify some similar and some distinct patterns. The first quartile is always close to zero and the median increases slightly in the first rounds, something we also observed for S1.5. In contrast to that treatment, now the average and the third quartile fluctuate extremely in the first rounds with the average being substantially higher than the third quartile in many occasions. This is not the case anymore in later rounds and therefore a clear sign of learning. We want to focus on mature behavior and therefore discard the data of the first 25 rounds for all treatments for the remainder of this paper. In all treatments behavior has settled down by then.

In the baseline treatment, subjects played a hundred independent second-price sealed-bid auctions. Behavior in one of the groups (the first group) is very different from the other groups. Two subjects in this group lost part of their initial endowment of $€ 5$.- and received $€ 4.80$ and $€ 2.80$ respectively. These two subjects were bidding very aggressively throughout all auctions and their overbidding did not decrease even though they made losses. In the last 25 rounds their overbidding was very volatile and averaged 12.50 and 26.24. Furthermore, respectively five and twelve times they received a negative payoff from an auction during the last 50 auctions (25 rounds). The other two participants in this group played approximately according to theory but still were not able to earn more than about $€ 10$.-. The other eight groups in S1.0 earned on average $€ 13.60$ with a minimum of $€ 10.50$ whereas this group earned only $€ 6.83$ on average. Although we have nine independent observations for this treatment, tests across treatments are influenced by the behavior in this group. Since the behavior in this group is quite anomalous compared to the other groups in this treatment, we also discuss the results of tests from which we exclude data from the first group of S1.0.

\subsection{Efficiency}

Although the presence of positive synergies changes the equilibrium bidding strategy, it should not influence the efficiency of the first auction of a round. All risk-neutral bidders add the same positive constant to their bid and hence the bidder with the highest valuation still wins. To see whether this indeed holds true for our experiment we compare both the efficiency and the number of times the auction is completely efficient across treatments.

We measure the efficiency in the conventional way, namely as the winner's valuation divided by the highest valuation a subject had. This measure itself is not interesting, since 
it is responsive to the scale from which the valuations are drawn, but comparing the values across treatments can be informative. ${ }^{6}$ We also report the relative occurrence of a completely efficient auction. Although this measure is not that commonly used and insensitive to the degree of inefficiency, it is not responsive to scale and therefore straightforward to interpret.

\begin{tabular}{lccc}
\hline & S1.0 & S1.5 & S2.0 \\
\hline Efficiency & 99.62 & 97.72 & 97.30 \\
Occurrence & 92.44 & 84.44 & 77.78 \\
\hline S1.0 & & 0.073 & 0.000 \\
S1.5 & 0.073 & & 0.136 \\
S2.0 & 0.000 & 0.136 & \\
\hline
\end{tabular}

Table 1: The efficiency and occurrence of an efficient auction in percentages. The two-sided MannWhitney $\mathrm{U}$ statistics are based on the average efficiency in a group.

As can be seen in the upper row of Table 1, the average efficiency in S1.0 is higher than in the treatments with synergies. The same is observed for the instances in which the auction is efficient and both measures of efficiency are lower the larger the upgrading is. The second part of the table contains the significance levels of a two-sided Mann-Whitney U test across treatments based on the average efficiency in a group. The efficiency in the first group of S1.0 is much lower than in the other groups and excluding this group decreases the significance of a comparison between S1.0 and S1.5 to 0.037. Thus although the difference between S1.0 and S1.5 is not significant at 5 percent when we include all groups, it is still reasonable to conclude that the efficiency in the two treatments with positive synergies is significantly different (lower) from that in the baseline treatment. It cannot be concluded that there is a significant difference between the efficiency in S1.5 and S2.0. Tests on the occurrence of a completely efficient auction support these insights.

Result 1. The presence of positive synergies reduces the efficiency in the first auction.

\subsection{Aggressive bidding}

The larger the expected benefit from upgrading, the more aggressive the bidding in the first auction should be. Therefore we expect the overbidding to be significantly higher, the larger the upgrading is. In the first part of Table 2 we report the overall average and median overbid per treatment. Although in the two treatments with positive synergies the overbidding is much lower than theory predicts, we do see that it increases with the synergy factor.

In the second part of the table we report the significance levels of a one-sided MannWhitney $U$ test across treatments which is based on the average overbid per group. It can be concluded that at a 5 percent significance level, the overbidding indeed increases significantly with the synergy factor. Excluding the first group of S1.0 leads to even higher significance

\footnotetext{
${ }^{6}$ See Ledyard et al. (1989) for a discussion on this.
} 


\begin{tabular}{lccc}
\hline & S1.0 & S1.5 & S2.0 \\
\hline Average & 4.23 & 8.12 & 12.16 \\
Median & 0.00 & 4.30 & 7.00 \\
\hline S1.0 & & 0.020 & 0.001 \\
S1.5 & 0.020 & & 0.047 \\
S2.0 & 0.001 & 0.047 & \\
\hline
\end{tabular}

Table 2: The average and median overbidding per treatment. The one-sided Mann-Whitney U statistics are based on the average overbidding per group.

levels for comparisons between this treatment and the other two. When we do the same analysis but then on the median overbid per group, the difference between S1.5 and S2.0 is not significant at any conventional level. Thus, although the average overbidding increases significantly with the synergy factor we do not find the same for the median overbidding.

Result 2. The larger the synergy factor, the more aggressive the average bidding in the first auction. Also the median bidding gets more aggressive when positive synergies are present, but there is no significant difference for the different synergy factors.

\subsection{Prices and revenues}

We will now analyze the effect the presence of synergies has on prices and revenue. In the first row of Table 3 it can be seen that the overall average and median price in the first auction increases with the synergy factor. However it can also be seen that the difference between S2.0 and S1.5 is smaller than between S1.5 and S1.0.

\begin{tabular}{lccc}
\hline & S1.0 & S1.5 & S2.0 \\
\hline Average & 65.24 & 71.07 & 75.39 \\
Median & 68.00 & 73.00 & 78.00 \\
\hline S1.0 & & 0.004 & 0.000 \\
S1.5 & 0.004 & & 0.129 \\
S2.0 & 0.000 & 0.129 & \\
\hline
\end{tabular}

Table 3: The average and median price per treatment. The one-sided Mann-Whitney U statistics are based on the average prices per group.

The second part of Table 3 reports the significance levels of one-sided Mann-Whitney U tests across treatments. The tests are based on the average price per group and basing the tests on the median price per group leads to similar results. Indeed the average prices in the two treatments with positive synergies are significantly larger than in S1.0. The average prices in S1.5 and S2.0 do not differ significantly.

Result 3. The presence of synergies leads to a higher price in the first auction of a round. However, the price does not increase significantly when the synergy factor increases further. 
Revenues are always important for a seller. According to theory, the seller is the only person who benefits from the presence of synergies. For the moment we will only analyze whether the seller benefits from the synergies the bidders had. In the next subsection we will discuss the payoffs for the subjects.

\begin{tabular}{lccc}
\hline & S1.0 & S1.5 & S2.0 \\
\hline Average & 128.03 & 140.24 & 149.01 \\
Median & 129.00 & 141.00 & 149.00 \\
\hline S1.0 & & 0.001 & 0.000 \\
S1.5 & 0.001 & & 0.082 \\
S2.0 & 0.000 & 0.082 & \\
\hline
\end{tabular}

Table 4: The average and median revenue in ECU per treatment. The one-sided Mann-Whitney U statistics are based on the average revenue per group.

Although we saw that the difference between the prices in the first auction was not significant between S2.0 and S1.5, the difference in revenue from both auctions within a round might still be. The overall average and median revenue indeed increase with the synergy factor but again the difference between S2.0 and S1.5 is smaller than between S1.5 and S1.0. In the second part of Table 4 we observe similar results as for the price in the first auction. There is a significant difference between the revenue from S1.0 and the two treatments with synergies. The difference between S2.0 and S1.5 is not significant at 5 percent. Again the presence of synergies leads to a significant change, but the revenue is not as responsive to a further increase in the synergy factor as predicted by theory. Basing the statistical analysis on the median price per group leads to similar results.

Result 4. The presence of synergies leads to a higher revenue from a round. However, the revenue does not increase significantly when the synergy factor increases further.

Although the declining price anomaly is always observed in expectation for uniformly distributed valuations, it depends on the drawn valuations whether it is actually observed in a round. To see whether prices are actually declining we run a Wilcoxon signed ranks test on the prices in the first and second auction in each round per group. Keser and Olson (1996) mention that a simple comparison of the observations in which prices decline and increase is not correct since the price distributions of the units are not symmetric for homogeneous objects. We have heterogeneous objects where the valuations were drawn anew for each auction and therefore do not have this complication. In S1.0 there should be no price trend and therefore the tests are two-sided. In the treatments with positive synergies, declining prices should be observed and the reported test statistics are one-sided. Given the realizations of the valuations, prices should be significantly declining in both S1.5 and S2.0.

As can be seen in Table 5, for S1.0 there is no group for which we can reject that the prices in both auctions are equal. For the two treatments with positive synergies the equality 


\begin{tabular}{cccc}
\hline Group & S1.0 & S1.5 & S2.0 \\
\hline 1 & 0.797 & 0.467 & 0.043 \\
2 & 0.578 & 0.329 & 0.278 \\
3 & 0.921 & 0.336 & 0.265 \\
4 & 0.658 & 0.409 & 0.146 \\
5 & 0.556 & 0.044 & 0.497 \\
6 & 0.806 & 0.492 & 0.174 \\
7 & 0.329 & 0.497 & 0.455 \\
8 & 0.679 & 0.088 & 0.248 \\
9 & 0.679 & 0.282 & 0.398 \\
\hline
\end{tabular}

Table 5: Wilcoxon signed ranks test on the prices in the first and second auction per group. For S1.0 the tests are two-sided and for S1.5 and S2.0 the tests are one-sided.

of prices can also not be rejected for almost all groups. For both S1.5 and S2.0 prices are significantly declining in only a single group. Additionally, in S2.0 even at 10 percent we can reject the equality of prices for only one group.

Result 5. We do not observe declining prices when synergies are present.

\subsection{Payoffs}

According to theory the presence of positive synergies is not beneficial for bidders. First of all, bidders receive a negative payoff from a round with positive probability. Second, the expected payoff from a round is lower with than without synergies. In this subsection we will examine subjects' payoffs for both effects.

For each group we calculated the number of times a subject received a negative round payoff that was caused by the first auction of a round. Thus, to count as a round bankruptcy both the first auction and the round payoff had to be negative. This measure excludes negative round payoffs that were caused by the second auction, which are not stemming from the presence of synergies but due to standard overbidding. However, doing the analysis on all negative round payoffs leads to the same insights.

\begin{tabular}{lccc}
\hline & S1.0 & S1.5 & S2.0 \\
\hline Average & 2.67 & 4.89 & 5.33 \\
Median & 2.00 & 5.00 & 5.00 \\
\hline S1.0 & & 0.073 & 0.008 \\
S1.5 & 0.073 & & 0.441 \\
S2.0 & 0.008 & 0.441 & \\
\hline
\end{tabular}

Table 6: The average and median number of round bankruptcies per treatment. The exact one-sided Mann-Whitney U statistics are based on the number of round bankruptcies per group.

Given the theoretical probability with which the first auction winner receives a negative payoff from a round, we should observe approximately 0,7 and 10 round bankruptcies for 
respectively S1.0, S1.5 and S2.0. In Table 6 it can be seen that the average number of round bankruptcies for the baseline treatment is larger and for the two treatments with synergies is smaller than theory predicts. The average number of round bankruptcies increases with the synergy factor, but the median is identical for S1.5 and S2.0.

In Table 6 we also report the one-sided Mann-Whitney U statistics which are based on the number of round bankruptcies per group. When we exclude the first group of S1.0, which has eight round bankruptcies in the last 25 rounds according to the criterium used here, the average number of observed bankruptcies drops to 2. In Table 6 the difference between S1.0 and S1.5 is not significant at 5 percent but without this first group the significance level drops to 0.022 . The difference between S1.0 and S2.0 is always significant. Therefore we conclude that the number of round bankruptcies increases significantly when synergies are present. We cannot conclude that the number of round bankruptcies increases significantly when the synergy factor increases from 1.5 to 2.0 .

Result 6. The presence of positive synergies leads to significantly more round bankruptcies. However, the frequency with which round bankruptcies are observed is not as responsive to the synergy factor as predicted by theory.

So far we have observed that although the presence of positive synergies changes the sequential auction fundamentally, subjects' behavior does not differ significantly between the two treatments with positive synergies. Although the average overbidding in S2.0 is significantly larger than in S1.5, we cannot find significant differences in the median overbidding, first auction prices, seller's revenue and number of bankruptcies. The bidding does not get as aggressive as predicted by theory and this could be caused by the amount of bankruptcies experienced in the first 25 rounds. However, we do not find such a negative relation between overbidding in the last 25 rounds and the number of experienced (round) bankruptcies in the first 25 rounds. The modest increase in competitiveness in the synergy factor can thus not be attributed to an idiosyncratic response to experienced bankruptcy.

According to theory the expected payoff from a round decreases with the synergy factor because the bidding in the first auction gets more aggressive. The above results then suggest that lower payoffs might not be observed here because the bidding does not get sufficiently aggressive.

\begin{tabular}{lccc}
\hline & S1.0 & S1.5 & S2.0 \\
\hline Average & 227.49 & 247.54 & 322.69 \\
Median & 235.15 & 251.00 & 332.45 \\
\hline S1.0 & & 0.193 & 0.001 \\
S1.5 & 0.193 & & 0.004 \\
S2.0 & 0.001 & 0.004 & \\
\hline
\end{tabular}

Table 7: The average and median payment in ECU per treatment. The one-sided Mann-Whitney U statistics are based on the average payment per group. 
The upper part of Table 7 shows that the average and median payment to subjects is increasing in the synergy factor. In the second part of the table we report the significance levels of a one-sided Mann-Whitney $U$ test across treatments which is based on the average payment per group. The difference between S1.0 and S1.5 is not significant and the payment in S2.0 is significantly larger than in both. Of course, the extremely low earnings in the first group of S1.0 (125.00 on average) influences the test results. The average payment in S1.0 without this group increases to 240.31 and the significance levels of a comparison with S1.5 and S2.0 are 0.303 and 0.003 respectively.

Due to the synergies, the surplus to be divided in S1.5 is larger than in S1.0. However subjects do not significantly earn more, since the increase in total surplus is dissipated by the more aggressive bidding. An increase in the synergy factor increases the surplus to be divided further, but does not increase the price significantly (Result 3) and thus the payoffs bidders receive increase.

Result 7. There is no significant difference between the earnings in S1.0 and S1.5. The earnings in S2.0 are significantly larger than in the other two treatments.

\section{Behavioral aspects}

In the previous section the tests were based on group data. In this section we analyze subjects' behavior on an individual level. People rely on a limited number of heuristic principles that reduce the complexity of tasks. Although these heuristics are quite useful, they sometimes lead to systematic errors, because a slight change in the presentation of a problem can have a significant effect on the experimental outcome (Tversky and Kahneman, 1974). We first analyze whether there is a difference between the behavior in the first and second auction in S1.0. Then we test whether there is a relationship between the valuation and the overbid in the first auction of a round for each treatment.

In S1.0 one hundred independent second-price sealed-bid auctions are grouped into fifty rounds of two auctions each. We will now examine whether this presentation induces differences in behavior in both auctions in the last twenty-five rounds. Although it is not rational, subjects might bid less aggressive in the first auction since they have two chances to win in a round.

\begin{tabular}{lcc}
\hline & Auction 1 & Auction 2 \\
\hline Average & 4.23 & 4.58 \\
Median & 0.00 & 0.00 \\
\hline$b_{i}>v_{i}$ & $49 \%$ & $48 \%$ \\
$b_{i}=v_{i}$ & $47 \%$ & $47 \%$ \\
$b_{i}<v_{i}$ & $4 \%$ & $5 \%$ \\
\hline
\end{tabular}

Table 8: The average and median overbid and the bidding behavior compared to theory for the first and second auction in S1.0. 
In Table 8 it can be seen that the median overbids are equal and that the average overbid in the second auction is slightly higher than in the first auction. The percentages of truthful bids are equal and in the first auction there are more overbids than in the second auction. To test whether there is a significant difference in bidding behavior we do a Wilcoxon signed ranks test on the overbids in both auctions for each individual. At a significance level of 5 percent the null hypothesis can be rejected for only 1 out of 36 subjects. Also at $10 \%$ significance level we do not find more significant differences. Thus we do not find that the presentation of two auctions in a sequence per round leads to differences in behavior between both auctions.

Kagel and Levin (1993) find that in an experiment with five bidders 62 percent of all bids are above and 8 percent are below valuation. In Table 8 it can be seen that we observe much more bidding according to theory and less overbidding. However, we have many repetitions of the auction and only discuss mature behavior, whereas their frequencies include all observations. Also, we have four rather than five bidders in a group which might cause faster learning. Finally, 18 out of 36 subjects indicated to have come across at least some auction theory during their studies.

Result 8. We do not find framing effects in the baseline treatment.

Our final analysis concerns the relationship between the overbidding and valuation in the first auction. For the two treatments with positive synergies the overbidding in the first auction, which is the expected increase in the second auction payoff from winning the first, is based on the expected second auction valuations. The valuation in the first auction is uncorrelated to the valuation that will be drawn in the second auction. Consequently, the amount of overbidding should be completely independent of the first auction valuation.

To analyze the relationship between the amount of overbidding and the valuation in the first auction, we regress the overbid on the valuation for all observations in the last 25 rounds for each treatment. To correct for heterogeneity between groups we include a dummy for each group in the regression. Dependency within a group is corrected for by clustering observations from the same group. We include lagged overbids to take out dependency over rounds and also correct for heteroscedasticity. Any of the above independent variables is removed from the estimation if its significance is less than 5 percent. The estimation results can be seen in Table 9.

For S1.0 the intercept is not significantly different from zero, but for groups 1 and 3 the dummies are well above zero and significant. The coefficient of valuation is insignificant at 5 percent. When we exclude group 1, where the overbidding is much higher for high valuations than for low, the coefficient of valuation is also insignificant at 10 percent. Thus, the drawn valuation does not explain the overbidding in the baseline treatment. The regression for the second auction of a round in S1.0 leads to the same insights.

For S1.5 the constant is not significant, but the two lags of overbid capture the level 


\begin{tabular}{llrrrr}
\hline Treatment & Variable & Coefficient & Std. Error & \multicolumn{1}{c}{$t$} & $P>|t|$ \\
\hline S1.0 & Constant & -1.656 & 2.087 & -0.79 & 0.450 \\
& Group 1 & 7.757 & 0.523 & 14.84 & 0.000 \\
& Group 3 & 7.767 & 0.523 & 14.86 & 0.000 \\
& Valuation & 0.082 & 0.041 & 2.01 & 0.080 \\
& Adjusted $R^{2}=0.061$ & & & \\
\hline S1.5 & Constant & -0.452 & 0.692 & -0.65 & 0.532 \\
& Lag 1 & 0.430 & 0.087 & 4.96 & 0.001 \\
& Lag 2 & 7.767 & 0.099 & 3.64 & 0.007 \\
& Valuation & 0.041 & 0.015 & 2.78 & 0.024 \\
& Adjusted $R^{2}=0.550$ & & & \\
\hline S2.0 & Constant & -4.703 & 1.792 & -2.62 & 0.030 \\
& Group 7 & -2.085 & 0.613 & -3.40 & 0.009 \\
& Lag 1 & 0.140 & 0.034 & 4.09 & 0.003 \\
& Lag 2 & 0.415 & 0.044 & 9.34 & 0.000 \\
& Lag 3 & 0.197 & 0.013 & 15.13 & 0.000 \\
& Valuation & 0.157 & 0.048 & 3.24 & 0.012 \\
& Adjusted $R^{2}=0.492$ & & &
\end{tabular}

Table 9: The estimation results with overbid as dependent variable for each treatment.

of constant overbidding. Although the coefficient of valuation is small, it is positive and significantly different from zero. For S2.0 we have to include a dummy for group 7 and three lags. Although the constant is negative and significant, it is impossible to give an interpretation for this due to the lags. The coefficient of valuation is large and significant. A subject with a valuation of 100 overbids 15.54 more than a subject with a valuation of 1 . It is also noteworthy that the adjusted $R^{2}$ is much higher for the two treatments with synergies than for S1.0.

Result 9. When positive synergies are present, subject's overbidding in the first auction increases with the valuation. This effect is especially pronounced for S2.0.

People often estimate a probability or valuation by adjusting an initial value. This initial value, an anchor, can be an arbitrary number that is suggested by the formulation of the problem or is a straightforward reference point. Typically, the adjustment is insufficient and therefore different anchors yield different estimates. The dependency of the estimate on the initial value is called anchoring (Tversky and Kahneman, 1974).

The observed positive relationship between the overbid and valuation in S1.5 and S2.0 and the lack of such a relationship in S1.0 can be explained by anchoring. When subjects estimate their second auction valuation by taking the first auction valuation as reference point (anchor), the expected valuation for the second auction will increase with the valuation in the first auction. ${ }^{7}$ The higher the valuation of the second object, the larger the expected benefit

\footnotetext{
${ }^{7}$ Usually the term anchoring is used when the value of a completely distinct variable has an effect on the
} 
from synergies. Anchoring then leads to more overbidding in the first auction when the first auction valuation is high than when it is low.

If anchoring is indeed the explanation for the observed relationship between overbidding and valuation, we should not observe such a relationship for S1.0 and the second auctions in S1.5 and S2.0. The estimation results for the second auction of S1.0 are similar to those for the first, which are reported in Table 9, and thus do not display any significant relationship between the overbid and valuation. A regression on the overbids in the second auction of a round for the two treatments with positive synergies is not feasible due to the upgraded valuations that are above 100. Any bid above 100 is then consistent with theory and the enormous variability of these bids influences a regression with all observations substantially. Excluding valuations above 100 skews the results because we then remove 151 observations above 66.67 for S1.5 and 242 observations above 50.00 for S2.0. Still, comparing the estimation results for the first auction for the two treatments with positive synergies to those for the baseline treatment shows that our results are consistent with anchoring.

A comment concerning the regressions is that bids had to be nonnegative. Underbidding is then much more restricted at low valuations than at high valuations. However, the number of observations in which the overbid is negative is small for each treatment. The fraction of overbids that is smaller than -2 is negligible and caused by a small group of subjects. The upper bound on bidding was that high that no overbid came even close to it and therefore also did not influence our results. Finally, all subjects filled out control questions before the experiment started and one of the questions explicitly tested whether subjects understood that there was no relationship between the valuation drawn for the first auction and the valuation drawn for the second auction. Therefore the results cannot be attributed to a misunderstanding of the relationship between the drawn valuations in both auctions.

Although we think that the increase in overbid can be attributed to anchoring, it cannot be neglected that risk behavior or loss aversion may play a role. Namely, it is under risk neutrality that theory predicts the overbid to be independent of the value. However, if we assume bidders to be risk averse, a win in the second auction becomes less important for the first auction winner relative to the first auction losers. Therefore, the option value effect of winning in the first auction seems to be decreasing in the level of aversion towards risk. In addition, the option value of winning is expected to be decreasing in the expected payoff for the first auction, which is in turn positively related to the valuation drawn for the first auction. Hence, it is more likely to expect that the overbid is decreasing in the valuation than it to be increasing in the valuation. In order to guarantee ex ante efficiency - that is, the bidder with the highest valuation in the first auction to win the first auction - the overbid should then be constant. Efficiency is expected to be satisfied in equilibrium, since the second auction valuations are independent from the first auction valuations. All in all, we do not think risk

estimation of a variable of interest. Although here the two variables of interest are both valuations, we would still like to call this anchoring, since the valuations are completely uncorrelated. 
aversion explains the increase in overbid. Regarding loss aversion, although theoretically we are not able to rule out a dependency of the overbid on the valuation, experimentally we did not find a negative relation between overbidding in the last 25 rounds and the number of experienced (round) bankruptcies in the first 25 rounds. This makes it unlikely that the observed value-dependent overbidding can be attributed to loss aversion.

\section{Conclusion}

Many auction settings can be characterized as being sequential in nature and synergies are often present. Most theoretical and experimental research so far only discussed revenues and price trends. However, theoretically it can be shown that in the setting considered here, the presence of positive synergies can have counter-intuitive consequences for bidders. Namely, the presence of synergies leads to more aggressive bidding which makes subjects lose not only all benefits from synergies but also part of their payoff without synergies. This can even result in bankruptcies. To see whether all these gloomy theoretical predictions will indeed be observed we conducted an experimental analysis. The experimental results can give interesting insights for government procurement and other sequential auction settings.

We find that the presence of positive synergies indeed changes the auction fundamentally. But, the consequences of the synergies are not as bleach as predicted by theory. The efficiency is lower when synergies are present and the average overbidding increases with the size of the synergy factor. The latter leads to an increase in the number of bankruptcies that are observed. However, bidding does not get as aggressive as predicted by theory. Especially the responsiveness to an increase in the size of the synergy factor is much smaller than predicted. Consequently we find that bidders do benefit from synergies. The seller benefits from the synergies but not as much as expected. With respect to price trends we find that the price in the first auction of a round does not increase enough to observe declining prices.

The experimental results can also be analyzed for biases in subjects' behavior. The presentation of grouping a hundred independent second-price sealed-bid auctions into rounds of two auctions each in the baseline treatment does not lead to differences between behavior in the first and second auction of a round. The valuations in both auctions of a round are drawn completely independently, but anchoring will make subjects with a high valuation in the first auction expect a high valuation in the second auction. Expecting a higher second auction valuation will lead to more overbidding in the first auction. Indeed a positive relationship is found between the first auction valuation and the first auction overbid. Especially for the treatment with large synergies this effect is prominent.

\section{References}

1. Ashenfelter, O. (1989). How auctions work for wine and art. Journal of Economic 
Perspectives, 3 (3), 23-36.

2. Ashenfelter, O., Genesove, D. (1992). Testing for price anomalies in real-estate auctions. American Economic Review, 82 (2), 501-505.

3. Beggs, A., Graddy, K. (1997). Declining values and the afternoon effect: Evidence from art auctions. RAND Journal of Economics, 28 (3), 544-565.

4. Black, J., Meza, D. de (1992). Systematic price differences between successive auctions are no anomaly. Journal of Economics and Management Strategy, 1 (4), 607-628.

5. Branco, F. (1997). Sequential auctions with synergies: An example. Economics Letters, $54(2), 159-163$.

6. Brenner, D., Morgan, J. (1997). The Vickrey-Clarke-Groves versus the simultaneous ascending auction: An experimental approach. Working paper. Princeton University.

7. Burns, P. (1985). Experience and decision-making: A comparison of students and businessmen in a simulated progressive auction. Research in Experimental Economics III, 139-157.

8. Cramton, P. (2002). Spectrum auctions. In: Cave, M., Majumdar, S., Vogelsang, I., Handbook of telecommunications economics. Amsterdam: Elsevier, pp. 605-639.

9. Engelbrecht-Wiggans, R. (1994). Sequential auctions of stochastically equivalent objects. Economics Letters, 44 (1-2), 87-90.

10. Englmaier, F., Guillen, P., Llorente, L., Onderstal, S., Sausgruber, R. (2004). The chopstick auction: A study of the exposure problem in multi-unit auctions. Working paper. Fondazione Eni Enrico Mattei.

11. Février, P., Linnemer, L., Visser, M. (2004). Buy or wait, that is the option: The buyer's option in sequential laboratory auctions. RAND Journal of Economics, forthcoming.

12. Fischbacher, U. (1999). Z-Tree: Zurich toolbox for readymade economic experiments. Working paper 21. Institute for Empirical Research in Economics, University of Zurich.

13. Güth, W., Ivanova-Stenzel, R., Wolfstetter, E. (2005). Bidding behavior in asymmetric auctions: An experimental study. European Economic Review, 49 (7), 1891-1913.

14. Huck, S., Norman, H.T., Oechssler, J. (2004). Two are few and four are many: Number effects in experimental oligopoly. Journal of Economic Behavior and Organization, 53 (4), 435-446.

15. Isaac, R., James, D. (2000). Robustness of the incentive compatible combinatorial auction. Journal of Experimental Economics, 3, 31-54. 
16. Jeitschko, T.D., Wolfstetter E. (2002). Scale economies and the dynamics of recurring auctions. Economic Inquiry, 40 (3), 403-414.

17. Kagel, J., Harstad, R., Levin, D. (1987). Information impact and allocation rules in auctions with affiliated private values: A laboratory study. Econometrica, 55 (6), 12751304 .

18. Kagel, J., Levin, D. (1993). Independent private value auctions: Bidder behavior in first-, second- and third-price auctions with varying number of bidders. Economic Journal, 103, 868-879.

19. Kagel, J., Levin, D. (2005). Multi-unit demand auctions with synergies: Behavior in sealed-bid versus ascending-bid uniform-price auctions. Games and Economic Behavior, 53 (2), 170-209.

20. Keser, C., Olson, M. (1996). Experimental examination of the declining price anomaly. In: Ginsburgh, V., Menger, P.M., Economics of the arts: Selected essays. Amsterdam: Elsevier, pp. 151-175.

21. Ledyard, J., Porter, D., Rangel, A. (1997). Experiments testing multiobject allocation mechanisms. Journal of Economics and Management Strategy, 6, 639-675.

22. Leufkens, K., Peeters, R., Vermeulen, D. (2006). Sequential auctions with synergies: The paradox of positive synergies. METEOR Research Memorandum 06/018, Universiteit Maastricht, pp. 1-19.

23. McAfee, R.P., Vincent, D. (1993). The declining price anomaly. Journal of Economic Theory, 60 (1), 191-212.

24. Neugebauer, T., Pezanis-Christou, P. (2005). Bidding behavior at sequential first-price auctions with(out) supply uncertainty: A laboratory analysis. Journal of Economic Behavior \& Organization, forthcoming.

25. Plott, C. (1997). Laboratory experimental testbeds: Application to the PCS auction. Journal of Economics and Management Strategy, 6, 605-638.

26. Reiß, J.P., Schöndube, J.R. (2002). On participation in sequential procurement auctions. Working Paper. University of Magdeburg.

27. Tang Sørensen, S. (2006). Sequential auctions for stochastically equivalent complementary objects. Economics Letters, 91 (3), 337-342.

28. Tversky, A., Kahneman, D. (1974). Judgement under uncertainty: Heuristics and biases. Science, 185, 1124-1131. 
29. Weber, R.J. (1983). Multiple-objects auctions. In: Engelbrecht-Wiggans, R., Shubik, M., Stark, R.M., Auctions, bidding and contracting: Uses and theory. New York: New York University Press, pp. 165-194.

30. Yildirim, H. (2004). Piecewise procurement of a large-scale project. International Journal of Industrial Organization, 22, 1349-1375.

\section{Appendix}

\section{A Experimental instructions}

Here we will give the instructions for the baseline treatment and the treatment with synergy factor 2.0. When there is difference between the instructions, the instructions for S1.0 will be written between \{\} and the instructions for S2.0 treatment will be written between [ ].

Dear participant,

thank you for taking part in this experiment.

This experiment will last about 1.5 hours and you will be compensated according to your performance. In order to ensure that the experiment takes place in an optimal setting, we would like to ask you to follow the general rules during the whole experiment:

- Do not communicate with your fellow students! Even though the experiment may get exiting at times, it is very important that you remain silent through the proceedings.

- Please, switch off your mobile phone!

- Please read the instructions carefully! It is important that you understand the rules of the experiment. The instructions are identical for all participants. If something is not explained well, please raise your hand. Do not ask the question out loud, but wait until one of the experimenters approaches you to answer the question privately.

- You may make notes on the instruction sheets.

- After the experiment please remain seated until you are paid off.

- If you do not obey to the rules, the data becomes useless for us. Therefore we will have to exclude you from this experiment and you will not receive any compensation.

Your decisions are anonymous. Neither your fellow students nor anybody else will ever learn them from us. 
General set-up In this experiment all of you are buyers of a fictitious object that is auctioned off. You can earn ECUs (Experimental Currency Unit) which will be exchanged into Euros at the end of the experiment. The exchange rates will be given in the instructions below.

If you win an auction you do not receive the object but you receive an amount of money equal to your value of the object $v$ which is expressed in ECUs. In return you have to pay the price $p$ resulting from the auction. Thus you receive a payoff of $v-p$ ECUs. The rules of the auction will be discussed below.

Before the experiment starts, you will be randomly divided into groups of 4 potential buyers. You will not know the 3 potentials buyers you are matched with. The groups remain unchanged throughout the whole experiment.

This experiment consists of 50 rounds. Each round consists of 2 auctions which are held after each other. Now we will explain the procedures in each round.

Auction rules In each auction you and the 3 other potential buyers in your group will be bidding for a single object that is auctioned off.

In each auction the following happens. First you observe your value of the object. Then all of you are asked to submit a bid. Your bid can be any nonnegative number.

Within each group, the winner is the subject who submitted the highest bid. In case the highest bid was submitted by more than one subject, the computer will randomly select a winner among those subjects. The price the winner has to pay will be the highest bid among the subjects that did not win the object. The payoff to the winner will be the difference between his value $v$ and the price he has to pay $p$. All other subjects get a payoff of 0 .

Auction 1 The proceedings in the first auction of each round are as follows.

First your value of the object will be determined. For each subject this value will be an independently drawn integer between 0 and 100 with each number being equally likely. Your value will only be known to you.

After observing your value all of you are asked to submit a bid. Thus you will submit this bid after observing your value of the object but without observing the values or bids of the other subjects. To submit a bid you can fill in the number in the box and click on submit. Notice that your bid is not restricted to the interval $[0,100]$, thus bids higher than 100 are allowed. 


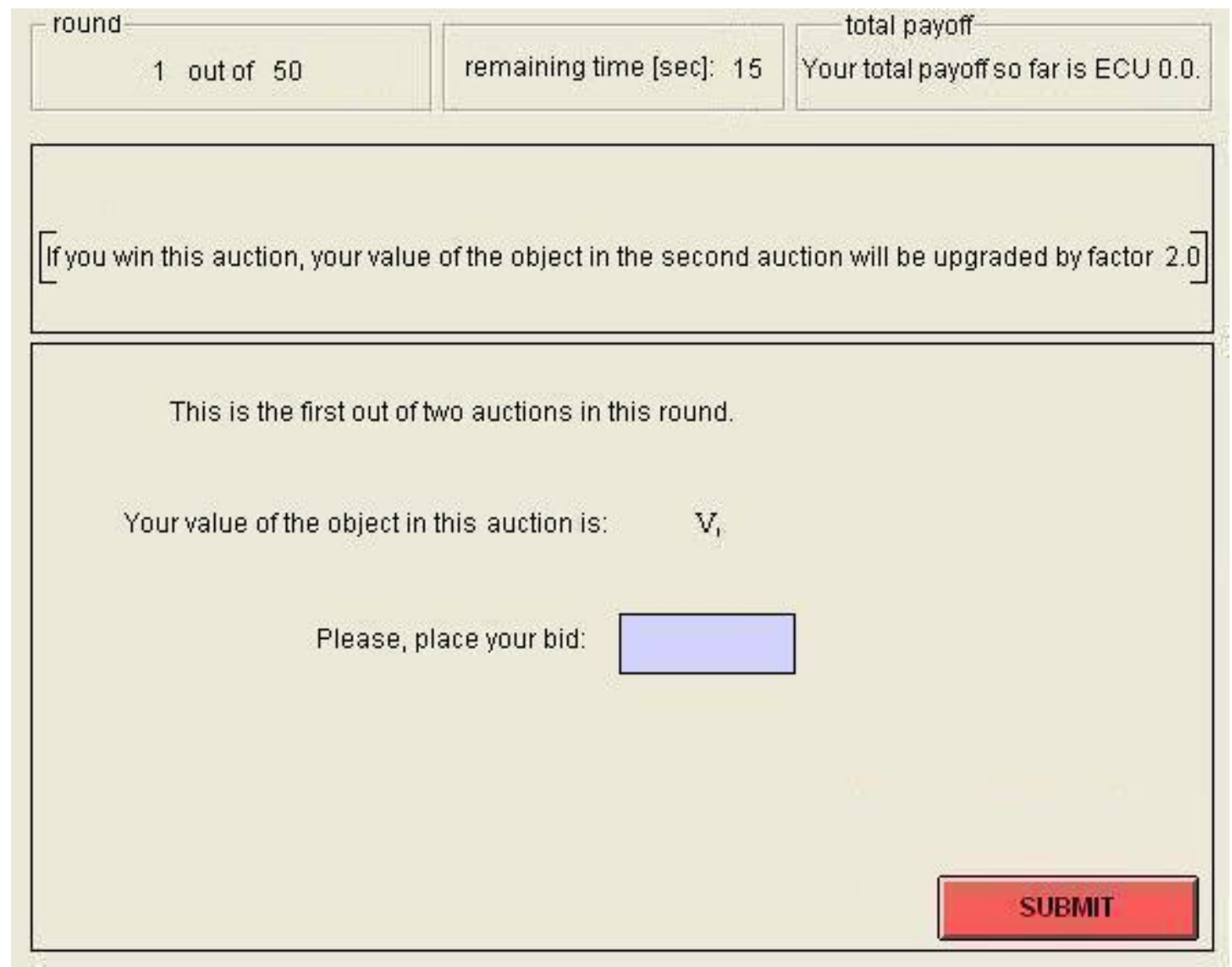

Figure 1: illustration of bidding in auction 1. Your value in the first auction is $v_{1}$. To make a bid you can enter a number in the corresponding box and click on submit. The screen also shows that this is the first out of 50 rounds and that your total payoff of all previous rounds is 0.0 .

[ The meaning of the sentence 'If you win this auction, your value of the object in the second auction will be upgraded by factor 2.0' will be clarified below. ]

After all of you submitted a bid, the winner and the price will be determined according to the rules mentioned above. The following feedback on the result of the auction will appear on your screen. Click on continue when you are ready for the second auction of this round. 


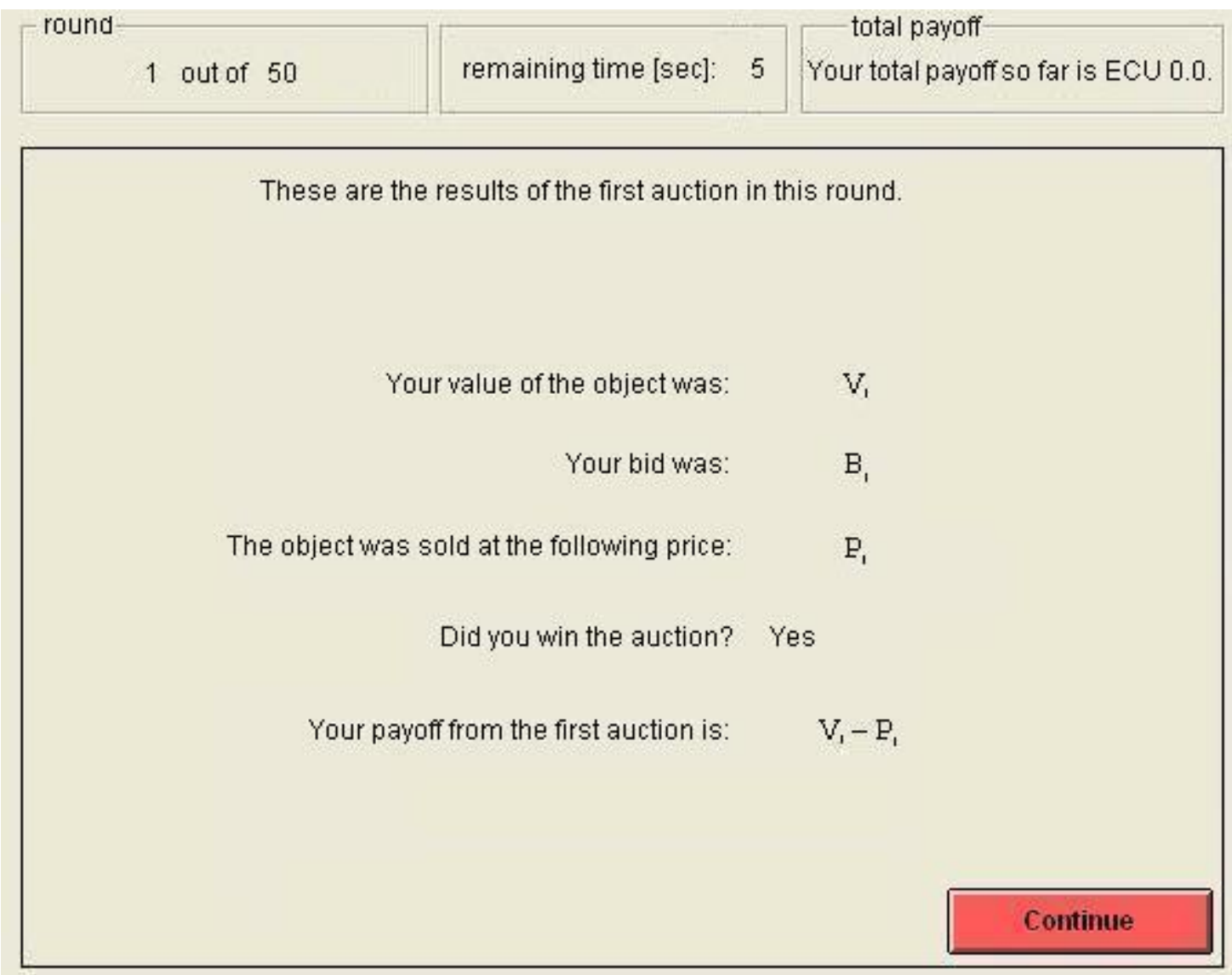

Figure 2: illustration of the results of auction 1 . Your value was $v_{1}$ and your bid was $b_{1}$. You won the auction and the price you have to pay is equal to $p_{1}$. Consequently your payoff from the first auction in this round is $v_{1}-p_{1}$.

Auction 2 The proceedings in the second auction of each round are as follows.

A new value of the object will be determined for each subject and this will again be an independently drawn integer between 0 and 100. Again each number is equally likely and your value will only be known to you.

[ In each group, the new value of the subject that won the first auction will be upgraded by factor 2.0. Thus the actual value for the subject that won the first auction will be a number between 0 and 200. The new values of the three other subjects will not be upgraded. Your screen will list both your value and your possibly upgraded value. ]

After observing your [upgraded] value all of you are asked to submit a bid. Again notice that your bid is not restricted to the interval $[0,100]$. 


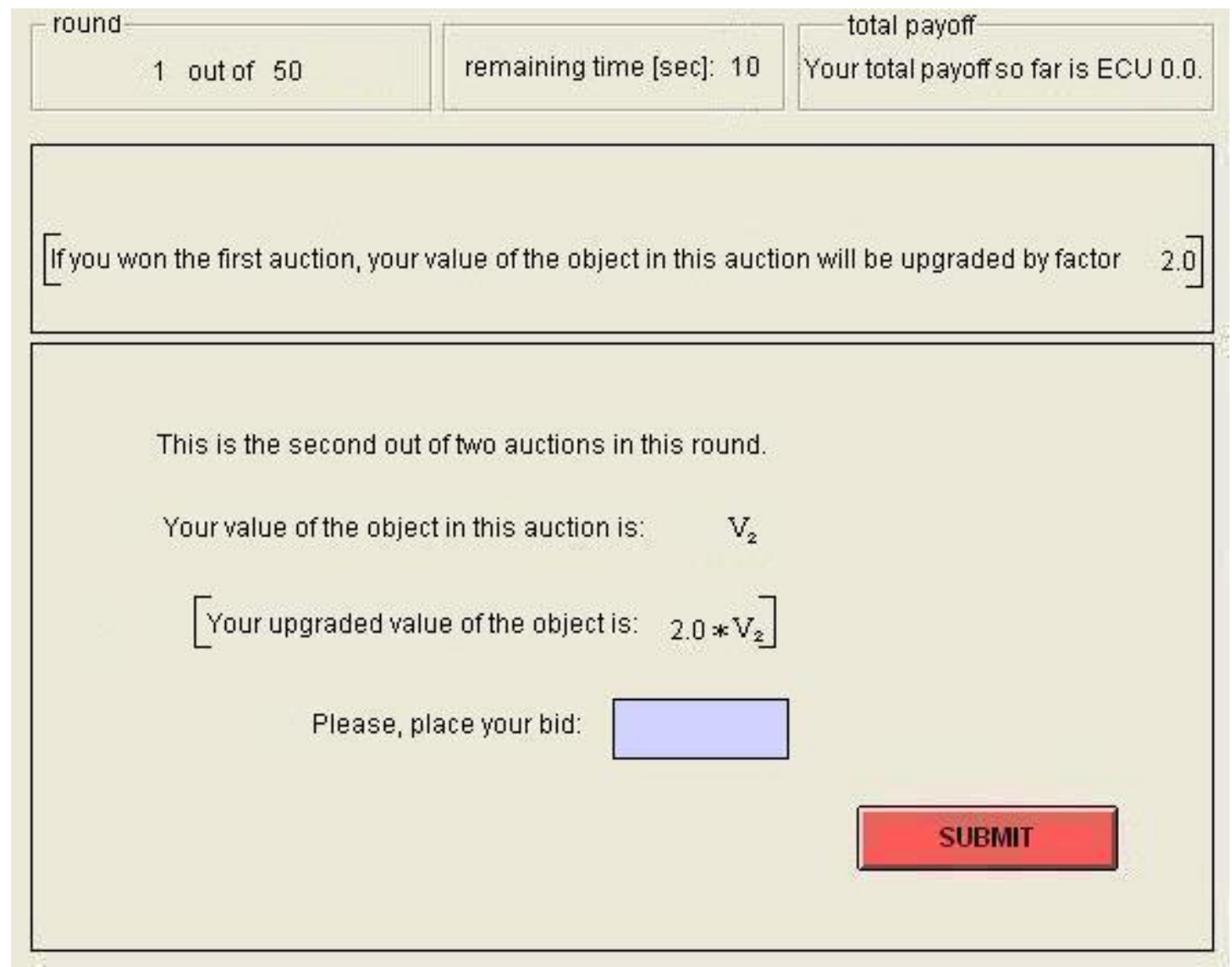

Figure 3: illustration of bidding in auction 2.

$\left\{\right.$ Your value in the second auction is $v_{2}$. To make a bid you can enter a number in the corresponding box and click on submit. $\}$

[ Since you won the first auction, your drawn value $v_{2}$ is upgraded by factor 2.0. Hence your upgraded value is 2.0 times $v_{2}$. For the three subjects that did not win the first auction, their upgraded value will be equal to their value. To make a bid you can enter a number in the corresponding box and click on submit. ]

After all of you submitted a bid, the winner and the price will be determined according to the rules mentioned above. The following feedback on the result of the auction will appear on your screen. 


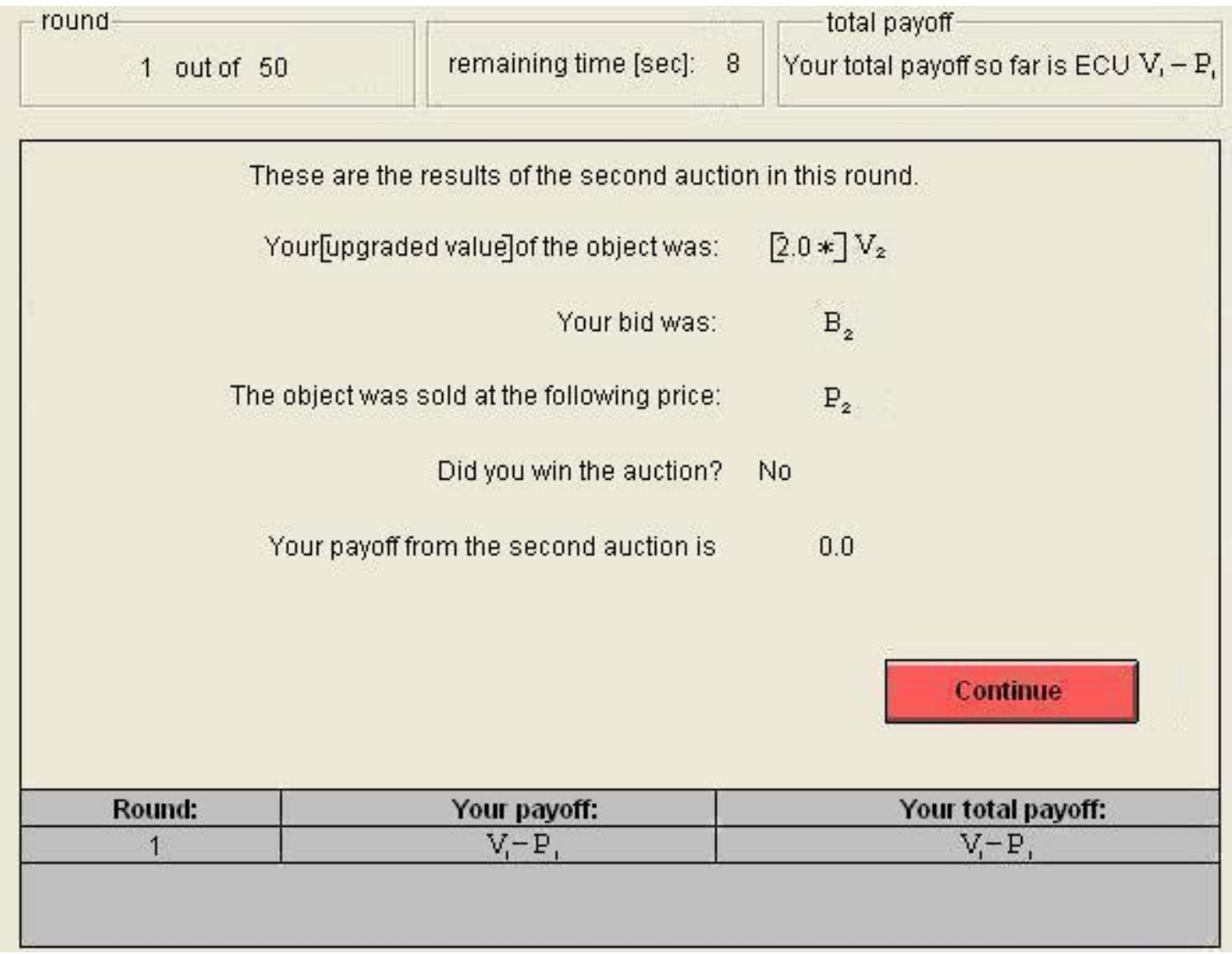

Figure 4: illustration of the results of auction 2. Your value was $v_{2}$ [ and since you won the first auction your upgraded value was $2.0 * v_{2}$. ]

Your bid was $b_{2}$ and you did not win the auction. Consequently your payoff from the second auction in this round is zero. Your payoff from the round is the sum of the payoffs of both auctions and thus in this case $v_{1}-p_{1}$. This was the first round and therefore the total payoff in the upper right corner changes from 0.0 into $v_{1}-p_{1}$.

This ends the round and the first auction of a new round starts after all of you clicked Continue. In total you will participate in 50 rounds of 2 auctions each.

After the last round of the experiment, we would like to ask you to complete a short questionnaire that will appear on your screen. Payments will be made by the experimenters afterwards.

ECUs are transformed into Euros according to the following conversion rate:

$\{1 \mathrm{ECU}=0.02$ Euro. You will get an initial budget of 5 Euro (250 ECU). $\}$

[ $1 \mathrm{ECU}=0.026$ Euro. You will get an initial budget of 5 Euro (187.50 ECU). ]

Note that this initial budget is not taken into account in the total payoff reported on your screen. If you make losses in an auction these will be deducted from the sum of your previous gains and the initial budget. Note that if the losses exceed previous 
gains and your initial budget, we will ask you to pay the difference. You will receive your final payment, thus the initial budget plus or minus your total payoff, in cash at the end of the experiment.

Before we start with the experiment we would like you to answer the questions on the next page. One of the experimenters will go around and check the answers and discuss any problems. 


\section{Control questions}

The questions between [ ] were only used in treatments S1.5 and S2.0.

Please answer the following questions. When you are finished, please raise your hand. One of the experimenters will come to you and check whether everything is correct.

1.) Suppose you have a value of 86 for the object. What can you conclude about the values of the three other potential buyers?

_ Their value is also 86.

_ Their value might be 86 and might be different from that.

_ Their value is different in any case.

2.) Suppose the four participants A, B, C, D submitted the following bids: A submitted 46, B submitted 93, C submitted 74, and D submitted 7. Who wins the auction?
$-\mathrm{A}$
$-\mathrm{B}$
$-\mathrm{C}$
$-\mathrm{D}$

3.) What price does this subject have to pay?
$-46$
$-93$
$-74$
$-7$

4.) Suppose you have a value of 45 in the first auction. What can you conclude about your value in the second auction before upgrading?

_ The value will also be 45 .

_ The value might be 45 and might be different from that.

_ The value is different in any case.

[5.) Suppose you did not win the first auction and your drawn value in the second auction is 80 . What is your upgraded value?

6.) Suppose you won the first auction and your drawn value in the second auction is 80 . What is your upgraded value?

7.) Suppose you buy the object for a price of 56 . Your value of the object is 65 . What is your payoff from this auction?

8.) Suppose you buy the object for a price of 31 . Your value of the object is 24 . What is your payoff from this auction? 


\section{B Post-experiment questionnaire}

Here we will give the questionnaire that subjects filled out after the experiment had finished. The question between [ ] was only used in treatments S1.5 and S2.0.

Subject ID (see the number on your computer):

Year of birth:

Gender:

Nationality:

Study:

Did you ever deal with auctions in one of your courses?

$\circ$ yes, thoroughly

$\circ$ yes, but superficially

○ never

Do or did you participate in online auctions (e.g. www.ebay.com)?

$\circ$ frequently

○ sometimes

o never

Did you participate in other auction experiments?

o more than once

○ once

$\circ$ never

Do or did you ever participate in auctions that are not an experiment or conducted online?

$\circ$ frequently

○ sometimes

$\circ$ never

[ With regards to the upgrading factor, would you have preferred:

○ no upgrading

- a smaller upgrading factor

- no change in the upgrading factor

- a larger upgrading factor ] 